\title{
HYDROGEN DIFFUSION IN AMORPHOUS FeCrB RIBBONS
}

\author{
Ladislav NOVÁK, Ján ZIMAN, Mária KOVALAKOVÁ, Mária KLADIVOVÁ \\ Department of Physics, Faculty of Electrical Engineering and Informatics, \\ Technical University of Košice, Park Komenského 2, 04200 Košice, Slovak Republic, tel.: +421 55602 2760, \\ e-mail: ladislav.novak@tuke.sk,jan.ziman@tuke.sk, maria.kovalakova@tuke.sk,maria.kladivova@tuke.sk
}

\begin{abstract}
The article deals with the study of hydrogen absorption (hydrogenation) and desorption (dehydrogenation) in amorphous ferromagnetic FeCrB ribbons prepared by rapid quenching from the melt. A simple theoretical model was proposed for description of hydrogen concentration and determination of diffusion coefficient in these materials. Using this model diffusion coefficient can be calculated using experimentally obtained values of average hydrogen concentration in the sample during dehydrogenation process. The values of diffusion coefficients are comparable with those obtained by hydrogen permeation test. The proposed method is not only simple but it also makes possible to determine diffusion coefficient under the same conditions as the changes of other properties of these materials during their dehydrogenation.
\end{abstract}

Keywords: hydrogenation, concentration, diffusion coefficient, amorphous ferromagnetic ribbons

\section{INTRODUCTION}

The parameters that characterize ferromagnetic material from the point of view of its possible technical applications are closely related to its physical properties and structure. Amorphous ferromagnetic alloys are materials widely used for electronics purposes. The study of their structural properties is very important because their magnetic, electric properties and stability in the operating conditions depend on their structure.

Heat treatment of amorphous materials is often used in the study of their structure and its possible modification although it can result in irreversible changes in amorphous structure. Significant predominantly reversible changes of some properties of amorphous ferromagnetic materials can be created by hydrogenation of amorphous material and subsequent dehydrogenation. Interaction of hydrogen with the structure of amorphous alloys has been intensively studied in last decades since hydrogen can influence electrical and magnetic properties of these materials and can also serve as a probe for the study of their structure [1]. That is why the study of hydrogen absorption (hydrogenation) and desorption (dehydrogenation) and determination of parameters of hydrogen diffusion in these alloys are of great importance. It has to be taken into account that this treatment is suitable only for materials which do not contain elements with a strong affinity to hydrogen. Basic parameter of hydrogen diffusion is diffusion coefficient that reflects mobility of hydrogen atoms in studied materials [2]. The standard method to study the diffusion of hydrogen in ribbon-shaped amorphous samples is hydrogen permeation test $[3,4]$. In this paper we propose an alternative method for determination of diffusion coefficient from the measurement of average hydrogen concentration in amorphous samples during their dehydrogenation. This method provides a possibility to determine the diffusion coefficient and the concentration profile during the dehydrogenation of the sample.

The main advantage of this method consists in the facts that it is simple and diffusion coefficient is determined under the same conditions as the changes of other properties of these materials during their dehydrogenation [5].

\section{EXPERIMENTAL}

The studied samples $\quad \mathrm{Fe}_{85} \mathrm{~B}_{15}, \quad \mathrm{Fe}_{81.5} \mathrm{Cr}_{0.8} \mathrm{~B}_{17.7}$, $\mathrm{Fe}_{80} \mathrm{Cr}_{4.3} \mathrm{~B}_{15.7}$ and $\mathrm{Fe}_{77.4} \mathrm{Cr}_{6.5} \mathrm{~B}_{16.1}$ were prepared by rapid quenching from the melt in KFKI MTA in Budapest. Elements of these materials do not exhibit affinity to hydrogen. The width $w$ of the samples was about $12 \mathrm{~mm}$ and thickness $L$ was a few tens of millimeters (in detail see the first two rows in Table 1). The length of samples used in experiments was $104 \mathrm{~mm}$. Atomic hydrogen was introduced into samples electrolytically from air side of ribbons [6] (Fig. 1). The duration of hydrogenation was 2 hours.

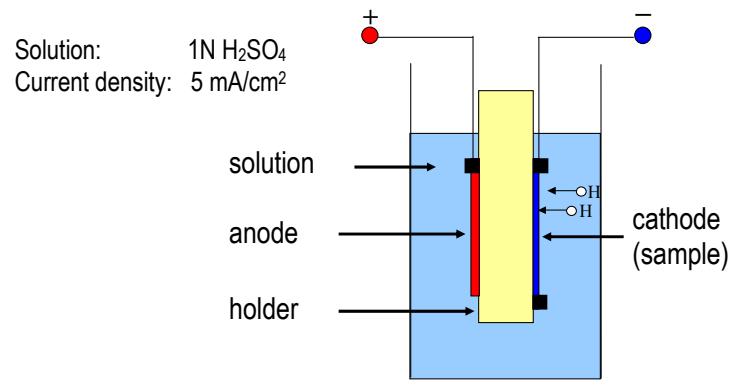

Fig. 1 Scheme of experiment - electrolytic hydrogenation

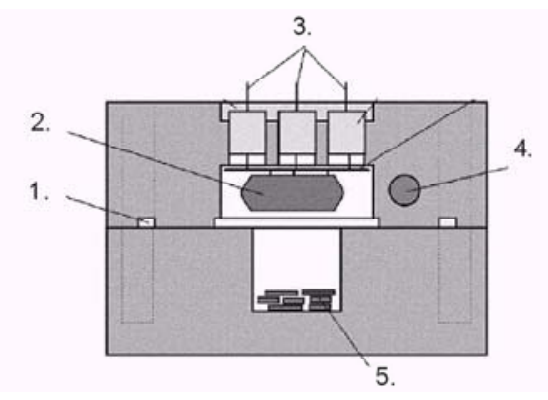

Fig. 2 Closed chamber for measuring of pressure and temperature of released hydrogen: 1 - sealing, 2 - pressure sensor, 3 - vacuum signal output, 4 - platinum thermometer, 5 -sample 
Then the sample was placed into a closed chamber. The hydrogen content was determined from the measured changes of pressure and temperature [7] (Fig. 2).

\section{THEORY}

Hydrogenation and dehydrogenation of ribbon-shaped amorphous FeCrB samples can be described by Fick's laws of diffusion

$$
\begin{aligned}
& j=-D \frac{\partial c}{\partial x} \\
& \frac{\partial c}{\partial t}=D \frac{\partial^{2} c}{\partial x^{2}}
\end{aligned}
$$

where $j$ is a flux of hydrogen atoms, $D$ is diffusion coefficient and $c$ is hydrogen concentration. For the material under study it is correct to assume that $D$ does not depend on $c$.
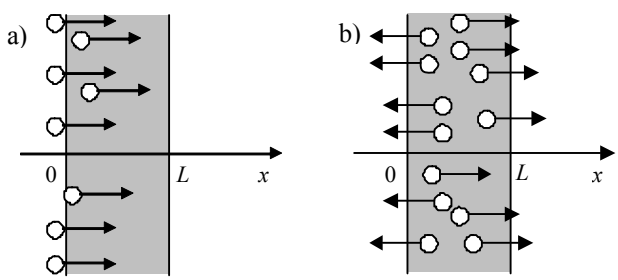

Fig. 3 Scheme of a) hydrogenation and b) dehydrogenation

The solution of Eq. 2 strongly depends on the initial and boundary conditions. If a ribbon-shaped sample of thickness $L$ is hydrogenated from one side, hydrogen atoms diffuse from one side of the sample where their concentration is of maximum value $c_{0}$ to the opposite side where the concentration is equal to zero (Fig. 3a), then the initial and boundary conditions are: $c(x, 0)=0$ for $x>0$ and $c(0, t)=c_{0}, c(L, t)=0$ for all $t>0$.

The solution of Eq. 2 satisfying these conditions is

$$
c(x, t)=c_{0}-c_{0} \frac{x}{L}-\frac{2 c_{0}}{\pi} \sum_{n=1}^{\infty} \frac{\sin \left(\frac{n \pi}{L} x\right)}{n} \mathrm{e}^{-\frac{n^{2} \pi^{2} D}{L^{2}} t}
$$

from which also the flux of hydrogen atoms $j(x, t)$ (Eq. 1) can be calculated (see Fig. 4).

Both quantities $c(x, t), j(x, t)$ can be measured on the opposite side of the sample $(x=L)$ in hydrogen permeation test. Fitting experimentally obtained $c(L, t)$, $j(L, t)$, values to the Eq. 3 and 1, the hydrogen diffusion coefficient can be obtained [3, 4].

Diffusion coefficient as well as the maximum of hydrogen concentration in the sample can be obtained from experimental data obtained during dehydrogenation also using a new and relatively simple procedure which will be described now in detail. As was mentioned above dehydrogenation process (Fig. 3b) obeys Eq. 2, for which the initial concentration of hydrogen atoms $c(x, 0)$ inside the sample is given by Eq. 3

$$
c(x, 0)=c_{0}-c_{0} \frac{x}{L}-\frac{2 c_{0}}{\pi} \sum_{n=1}^{\infty} \frac{\sin \left(n \frac{\pi}{L} x\right)}{n} \mathrm{e}^{-\frac{n^{2} \pi^{2} D}{L^{2}} t_{0}}
$$

where $t_{0}$ is the time of hydrogenation and the boundary conditions are: $c(0, t)=c(L, t)=0$ for all $t>0$, where $t$ is current time of dehydrogenation.
The concentration $c(x, t)$ satisfying these conditions is:

$c(x, t)=\frac{2 c_{0}}{\pi} \sum_{n=1}^{\infty} \frac{\sin \left(\frac{n \pi}{L} x\right)}{n}\left(1-\mathrm{e}^{-\frac{n^{2} \pi^{2} D}{L^{2}} t_{0}}\right) \mathrm{e}^{-\frac{n^{2} \pi^{2} D}{L^{2}} t}$

In the experiment an average hydrogen concentration $\bar{c}(t)$ is obtained. It can be also calculated using equation

$\bar{c}(t)=\frac{1}{L} \int_{0}^{L} c(x, t) d x$

This gives

$\bar{c}(t)=\frac{4 c_{0}}{\pi^{2}} \sum_{n=1}^{\infty} \frac{1-\mathrm{e}^{-\frac{(2 n-1)^{2} \pi^{2} D}{L^{2}} t_{0}}}{(2 n-1)^{2}} \mathrm{e}^{-\frac{(2 n-1)^{2} \pi^{2} D}{L^{2}} t}$

The experimental results of average hydrogen concentration vs. time can be fitted to the function $\bar{c}(t)$ (Eq. 7). The concentration $c_{0}$ and hydrogen diffusion coefficient $D$ are fitting parameters. Fitting function (Eq. 7) and experimental values of the concentration of $\mathrm{H}$ in amorphous ribbon $\mathrm{Fe}_{85} \mathrm{~B}_{15}$ are depicted in Fig. 4.

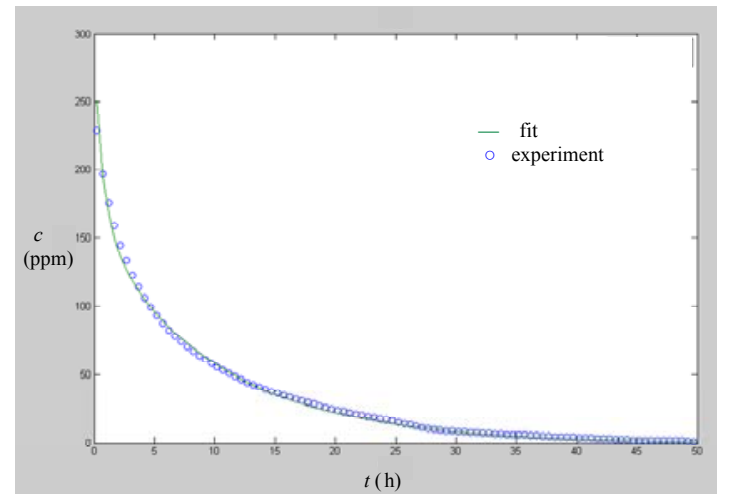

Fig. 4 Experimental results and theoretical dependence of the concentration of $\mathrm{H}$ in amorphous ribbon $\mathrm{Fe}_{85} \mathrm{~B}_{15}$ vs. time calculated using fitting parameters $c_{0}$ and $D$ obtained from the fit of experimental data during dehydrogenation (see Tab. 1). For fitting the least square method was used.

Using obtained fitting parameters $c_{0}$ and $D$ the profiles of concentration during hydrogenation and dehydrogenation can be calculated. In Figs. 5 and 6 these profiles are depicted for the same sample $\mathrm{Fe}_{85} \mathrm{~B}_{15}$.

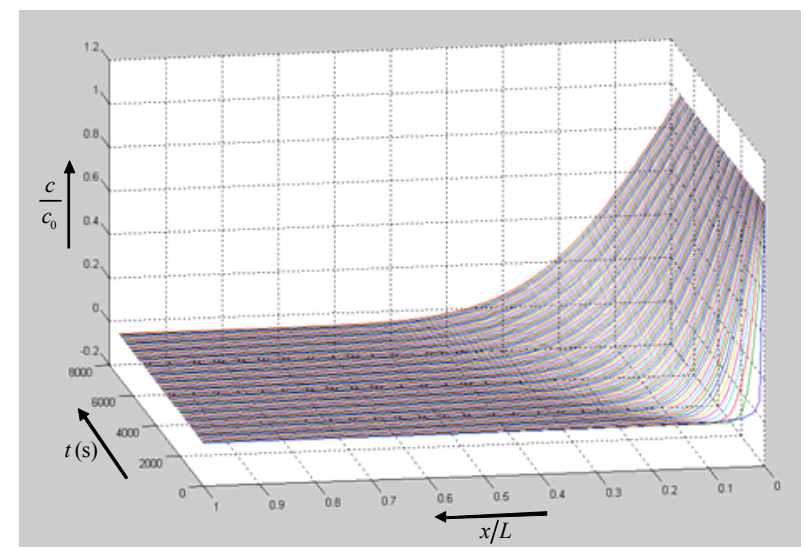

Fig. 5 Distribution of hydrogen in the amorphous ribbon $\mathrm{Fe}_{85} \mathrm{~B}_{15}$ for 2 hours (real time interval) of hydrogenation for $D=2.3 \times 10^{-15} \mathrm{~m}^{2} \mathrm{~s}^{-1}$, calculated using Eq. 3 . 


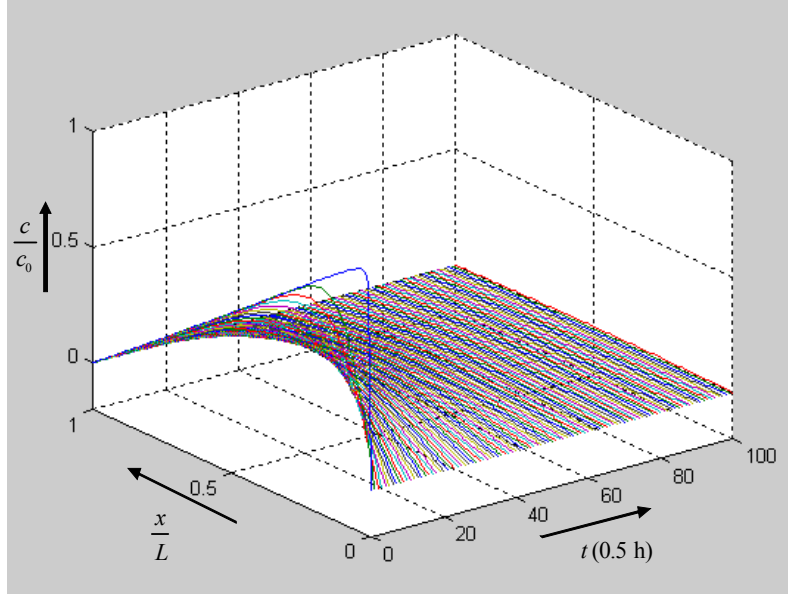

Fig. 6 Distribution of hydrogen in the amorphous ribbon $\mathrm{Fe}_{85} \mathrm{~B}_{15}$ for 50 hours (it is obvious that that time is enough for hydrogen to be released from the ribbon sample) of dehydrogenation for $D=2.3 \times 10^{-15} \mathrm{~m}^{2} \mathrm{~s}^{-1}$, calculated using Eq. 5 .

\section{RESULTS AND DISCUSSION}

In metals hydrogen atoms occupy interstitial sites. The maximum hydrogen concentration then can be 3.0 $[\mathrm{H} / \mathrm{Me}]$, however experimentally obtained values are much lower (e.g. for steel $1.8 \times 10^{-3}[\mathrm{H} / \mathrm{Me}]$, where Me instead of a chemical symbol of metal). The situation in amorphous materials is even more complicated since they are materials with only short-range order and hydrogen solubility is influenced also by the energy distribution of available interstitial sites [1,3].

The values of average hydrogen concentration in the studied samples obtained experimentally during dehydrogenation were fitted to the function $\bar{c}(t)$ (Eq. 7) using the least square method. The obtained values of maximum $\mathrm{H}$ concentration $c_{0}$ and hydrogen diffusion coefficient $D$ are listed in Tab. 1 .

Table 1 The values of width $w$, thickness $L$, maximum concentration $c_{0}$ and diffusion coefficient $D$ of samples: $\mathbf{A}-\mathrm{Fe}_{85} \mathrm{~B}_{15}, \mathbf{B}-\mathrm{Fe}_{81.5} \mathrm{Cr}_{0.8} \mathrm{~B}_{17.7}, \mathbf{C}-\mathrm{Fe}_{80} \mathrm{Cr}_{4.3} \mathrm{~B}_{15.7}, \mathbf{D}-\mathrm{Fe}_{77.4} \mathrm{Cr}_{6.5} \mathrm{~B}_{16.1}$

\begin{tabular}{c|cccc}
\hline Sample & A & B & C & D \\
\hline$w(\mathrm{~mm})$ & 11.8 & 11.5 & 11.3 & 12.2 \\
$L(\mathrm{~mm})$ & 0.029 & 0.042 & 0.030 & 0.023 \\
\hline$c_{0}(\mathrm{ppm})$ & 2160 & 830 & 575 & 680 \\
$\begin{array}{c}D \times 10^{15} \\
\left(\mathrm{~m}^{2} \mathrm{~s}^{-1}\right)\end{array}$ & 2.3 & 6.0 & 5.9 & 1.8 \\
\hline
\end{tabular}

Experimentally obtained values and corresponding fitted curves are shown in Fig. 7. Magnetic measurements on the samples studied in this paper revealed that chromium introduces stress in amorphous structure proportional to the $\mathrm{Cr}$ content [4].

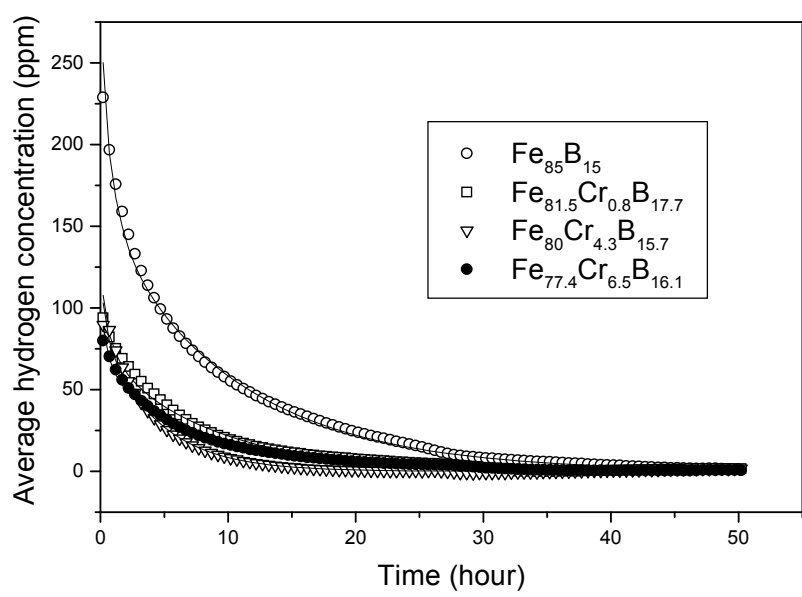

Fig. 7 Experimental and calculated values of average hydrogen concentration in $\mathrm{FeB}$ and $\mathrm{FeCrB}$ ribbons during dehydrogenation.

The stress centers are then probably less accessible for hydrogen atoms because for the samples with chromium admixture the $c_{0}$ values are distinctly lower than for $\mathrm{FeB}$ sample (Tab. 1). The calculated values of diffusion coefficient are of the same order as those obtained for amorphous FeNiMoB and NiP alloys by hydrogen permeation test $[1,4]$. Obtained values indicate that chromium up to 4.3 at. \% increases hydrogen mobility in amorphous materials since the values of diffusion coefficient for $\mathrm{Fe}_{81.5} \mathrm{Cr}_{0.8} \mathrm{~B}_{17.7}$ and $\mathrm{Fe}_{80} \mathrm{Cr}_{4.3} \mathrm{~B}_{15.7}$ are almost three times higher than for $\mathrm{Fe}_{85} \mathrm{~B}_{15}$ sample. However, further increase of $\mathrm{Cr}$ content results in material with lower hydrogen mobility $\left(\mathrm{Fe}_{77.4} \mathrm{Cr}_{6.5} \mathrm{~B}_{16.1}\right)$. This corresponds also with character of calculated distributions of concentration in samples depicted in the Figs. 8 and 9. In the samples $\mathrm{Fe}_{85} \mathrm{~B}_{15}$ and $\mathrm{Fe}_{77.4} \mathrm{Cr}_{6.5} \mathrm{~B}_{16.1}$ after 4 hour dehydrogenation these distributions are markedly asymmetrical. For $\mathrm{Fe}_{81.5} \mathrm{Cr}_{0.8} \mathrm{~B}_{17.7}$ after the same time the distribution is less asymmetric and for $\mathrm{Fe}_{80} \mathrm{Cr}_{4.3} \mathrm{~B}_{15.7}$ it is almost symmetrical.

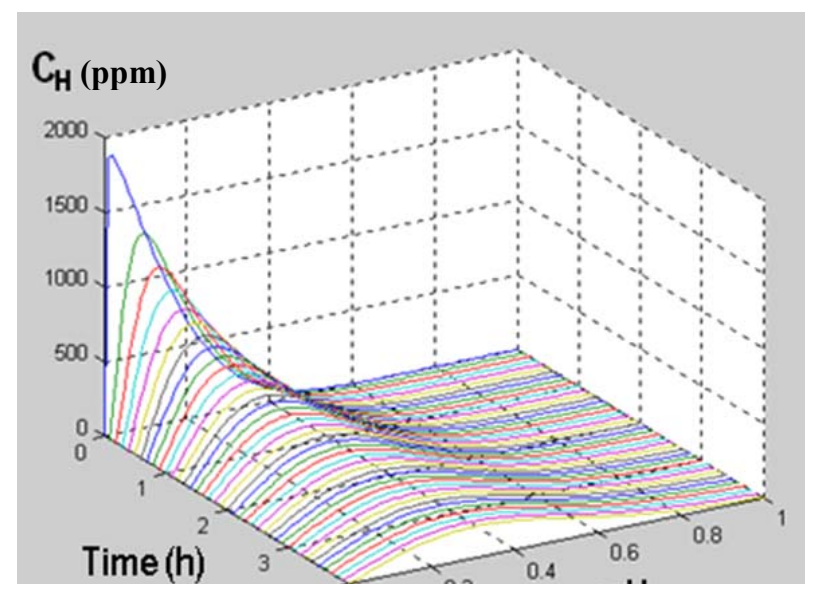

Fig. 8 Asymmetrical distribution of hydrogen in the amorphous ribbon $\mathrm{Fe}_{85} \mathrm{~B}_{15}$ for 4 hour dehydrogenation calculated using Eq. 5 


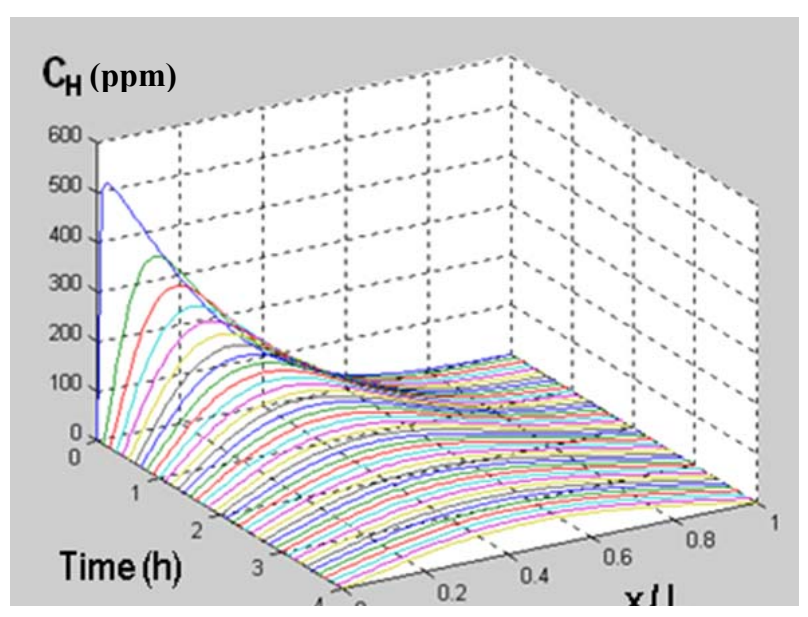

Fig. 9 Symmetrical distribution of hydrogen in the amorphous ribbon $\mathrm{Fe}_{80} \mathrm{Cr}_{4.3} \mathrm{~B}_{15.7}$ for 4 hour dehydrogenation calculated using Eq. 5

\section{CONCLUSION}

Proposed method for determination of diffusion coefficient and maximum hydrogen concentration in amorphous materials provides results comparable with those obtained by hydrogen permeation test. The values of maximum $\mathrm{H}$ concentration indicate that $\mathrm{Cr}$, probably due to the stress, which it brings to the structure, decreases the number of sites accessible by diffusing hydrogen. On the other hand its presence up to 4.3 at. \% increases hydrogen mobility observable in higher values of diffusion coefficient for $\mathrm{Fe}_{81.5} \mathrm{Cr}_{0.8} \mathrm{~B}_{17.7}$ and $\mathrm{Fe}_{80} \mathrm{Cr}_{4.3} \mathrm{~B}_{15.7}$ samples.

Proposed method can be also promising in evaluation of distribution of internal stresses depending on distribution of concentration of hydrogen in the sample, evaluation of constant of anisotropy for hydrogenated sample and its influence on magnetic behavior. This method can also provide some information on the relationships between bending the samples when hydrogenated from one side and distribution of $\mathrm{H}$ inside the samples [8].

\section{ACKNOWLEDGMENT}

This paper was developed within the project "Centre of Excellence for Integrated Research \& Exploitation of Advanced Materials and Technologies in Automotive Electronics" ITMS 26220120055.

\section{REFERENCES}

[1] ELIAZ, N. - ELIEZER, D.: Advanced Performance Materials, 6 (1999) 5.

[2] KIRCHHEIM, R.: Acta Metall., 30 (1982) 1069.

[3] dos SANTOS, D. S. - de MIRANDA, P. E. V.: Journal of Alloys and Compounds, 348 (2003) 241.
[4] dos SANTOS, D. S. - de MIRANDA, P. E. V.: Int. J. Hydrogen Energy, 23 (1998) 1011.

[5] KOVALAKOVÁ, M. - NOVÁK, L. - LOVAS, A. KOVÁČ, J.: Czech. J. Phys. 54, suppl. d (2004) 149.

[6] KOVALAKOVÁ, M. - NOVÁK, L. STANČÁKOVÁ, A.: 13. konferencia slovenských fyzikov, Slovenská fyzikálna spoločnost', (2004) 145.

[7] BÁN, K. - LOVAS, A. - NOVÁK, L. - CSACH, K.: Czech. J. Phys. 54, suppl.d (2004) 137.

[8] KOVALAKOVÁ, M. - KOLLÁR, P. - NOVÁK, L. - ŠEVČOVIČ, L.: J. Magn. Magn. Mater, 304 (2006) e648.

Received February 1, 2012, accepted June 30, 2012

\section{BIOGRAPHIES}

Ladislav Novák was born in 1948. In 1971 he graduated (MSc) from the Faculty of Science, University of P. J. Šafárik in Košice. He defended his CSc in 1984 and he became associate professor in 2007. Since 1998 he has been working at the Department of Physics, Faculty of Electrical Engineering and Informatics, Technical University in Košice. His research deals with magnetic properties of amorphous materials prepared by rapid quenching of the melt.

Ján Ziman was born in 1957. He graduated in solid state physics from Pavol Jozef Šafárik University in Košice. In 1994 he received the CSc. (PhD) degree from P.J. Šafárik University. He has been working at the Department of Physics, Faculty of Electrical Engineering and Informatics, Technical University Košice since 1983. Experimental study of ferromagnetic materials is a dominant field of his research work.

Mária Koval'aková was born in 1958. In 1982 she graduated from the Faculty of Science, Pavol Jozef Šafárik University in Košice. In 1999 she obtained her $\mathrm{PhD}$ degree at the Katholieke Universiteit in Leuven, Belgium. Since 1982 she has been working at the Department of Physics, Faculty of Electrical Engineering and Informatics, Technical University in Košice.. Her scientific research includes study of ferromagnetic materials and NMR study of zeolites and related materials.

Mária Kladivová graduated in mathematical physics in 1980. In 2008 she received the $\mathrm{PhD}$. degree from Pavol Jozef Šafárik University in Košice. She has been working at the Department of Physics, Faculty of Electrical Engineering and Informatics, Technical University of Košice since 1995. Study of ferromagnetic materials is a dominant field of her current research interest. 